\title{
Two new species of Russula (Russulales) from India
}

\author{
Das $\mathbf{K}^{1^{*}}$, Dowie $\mathrm{NJ}^{2}$, Li GJ ${ }^{3}$ and Miller $\mathrm{SL}^{2}$ \\ ${ }^{1}$ Botanical Survey of India, Cryptogamic Unit, P.O. Botanic Garden, Howrah 711103, India \\ ${ }^{2}$ Botany Department, University of Wyoming, Laramie, Wyoming 82071, USA \\ ${ }^{3}$ State Key Laboratory of Mycology, Chinese Academy of Sciences, Beijing 100101, China
}

Das K, Dowie NJ, Li GJ, Miller SL 2014 - Two new species of Russula (Russulales) from India. Mycosphere 5(5), 612-622, Doi 10.5943/mycosphere/5/5/2

\begin{abstract}
Two species: Russula shingbaensis ( $R$. subg. Heterophyllidia), characterized morphologically by greyish-green to slightly lilac pileus having tuberculately striate-sulcate margin, a stipe with a combination of white and vine colours, multichambered stipe context, indistinctive taste, spores ornamented with isolated warts, pilear elements with chains of globose to elongated inflated cells interspersed with comparatively narrow pileocystidia and $R$. thindii ( $R$. subg. Russula), characterized by red viscid pileus, broadly adnate to adnexed lamellae, reddish to vinaceous stipe, acrid taste, pale yellow spore print and pileocystidia without any incrustations were collected from Shingba Rhododendron wildlife sanctuary of North Sikkim (India) and are proposed here as new to science based on their morphological features and ITS-based phylogenetic tree. Macro- and micromorphological descriptions coupled with the illustrations are given for both the taxa. Their relationship with allied taxa are also discussed in the present paper.
\end{abstract}

Key words - Macrofungi - new taxa - phylogeny - Russulaceae - Sikkim - taxonomy

\section{Introduction}

The genus Rusula Pers. (Russulaceae) is the largest amongst the 80 genera accomodated in the order Russulales, the group that produces the most diverse forms of basidiomata including resupinate, discoid, effused-reflexed, clavarioid, pileate, or gasteroid and hymenophore configurations (Miller et al. 2006, Kirk et al. 2008). It can be easily separated from its sister genera Lactarius Pers. and Lactifluus (Pers.) Roussel in the field, mostly by absence of latex and micromorphologically by presence of complex agglomerated sphaerocytes and absence of pseudocystidia or lactifers (Verbeken 1996, Henkel et al. 2000). Russula is one of the major ectomycorrhizal genera and is represented by ca 130 taxa from India (Manjula 1983; Atri et al. 1994; Rawla 2001; Das \& Sharma 2005, Das et al. 2005, 2006a \& b, 2008, 2010, 2013; Pradeep \& Vrinda 2010; Mohanan 2011; Manimohan \& Latha 2011; Joshi et al. 2012; Das 2013).

Spreading over an area of $43 \mathrm{~km}^{2}$ Shingba Rhododendron wildlife sanctuary is geographically

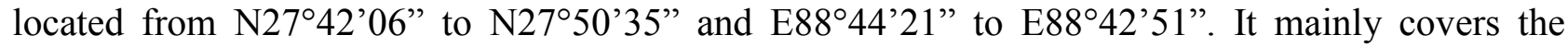
subalpine forested (coniferous or broad-leaf) area between Lachung and Yumthang valley in the North district of Sikkim, one of the small Himalayan state in India. Apart from different species of Rhododendron, this area is also dominated by ectomycorrhizal trees like, Abies, Tsuga, Larix, Acer and Betula. 
Thorough and systematic macrofungal explorations of this protected area had been initiated by the senior author since 2009. A number of ectomycorrhizal mushroom-samples were collected. After thorough examination of these samples, some appeared as interesting or undescribed taxa. Two of which namely, Russula shingbaensis and $R$. thindii are proposed herein as new species. Detailed macro- and micromorphological description coupled with the illustrations are given along with a phylogenetic tree based on ITS sequences.

\section{Materials \& Methods}

\section{Morphological study}

During repeated macrofungal forays in the monsoon season (July-September) the specimens were encountered. Macromorphological features were noted either in the field or in the base camp from the fresh samples. Field-photography was mainly carried out with a Nikon D300 camera. Colour codes and terms are after Kornerup \& Wanscher (1978), Henderson et al. (1969) and Kränzlin (2005) and given as 'a', 'b', and 'c' respectively in this manuscript. After the macromorphological characterization samples were dried with a Aluminium drier. Micromorphological characters were observed with a light microscope: Olympus CX 41 from free hand sections of dry samples mounted in a mixture of $5 \% \mathrm{KOH}$ and phloxin, $30 \%$ glycerol, and Melzer's reagent. Spore-measurements were recorded randomly in side view from twenty basidiospores. Spore-size and length/width ratios (Q) are given as: minimum-mean-maximum. Herbarium names follow Holmgren et al.(1990). Scanning Electron Microscope (SEM) images of basidiospores were obtained from dry spores (spore print) that were directly mounted on a doublesided adhesive tape pasted on a metallic specimen-stub and then scanned with gold coating at different magnifications in high vacuum mode $(30 \mathrm{KV})$ to observe patterns of spore-ornamentation. SEM work was carried out with a FEI's Quanta 200 model scanning electron microscope (SEM) installed at the S.N. Bose National Centre for Basic Sciences, Kolkata (India).

\section{DNA extraction, PCR and sequencing}

DNA was isolated from both samples and sequenced for subsequent identification. Specifically, excised tissue was freeze-dried and powdered using a FastPrep FP120 with $2.5 \mathrm{~mm}$ glass beads. Crushed tissue was rehydrated in 600ul of 2x CTAB buffer and DNA was extracted using a modified GeneClean III technique (Bergemann \& Miller 2002, Dowie et al. 2012). DNA was then diluted 1:10 for PCR amplification of ribosomal RNA using ITS1f and ITS4b primers following the well-established thermocycler protocols (White et al. 1990, Gardes \& Bruns 1993). The recovered gene regions partial $18 \mathrm{~S}$, the internal transcribed spacer 1 , a complete $5.8 \mathrm{~S}$, the internal transcribed spacer 2, and a partial 28S were then sequenced through the Macromolecular Analysis Core at the University of Wyoming USA, using an ABI3131x1 16-capillary Genetic Analyzer. Sequence contigs were assembled from generated chromatogram files from both markers and were manually checked using Sequencher 5.0 (Gene Codes Corporation).

\section{Phylogenetic analysis}

A Blast search in GenBank was performed for each query sequence to determine the most closely related taxa for molecular identification. A dataset was generated from the highest scored hits most relevant for identification, as well as from samples previously used in the phylogenetic reconstruction of Russula (Miller \& Buyck 2002). These 40 sequences included: $R$. adulterina (AY061651), R. aeruginea (KF002769), $R$. americana (HQ604839), $R$. americana (KC152211), $R$. amethystina (AY061653), $R$. aurantiaca (AY061658), $R$. claroflava (AY061665), $R$. curtipes (AY061668), $R$. decolorans (AY061670), $R$. drimeia (AY061672), $R$. drimeia (EU557320), $R$. emetica (AY061673), R. foetens (AY061677), $R$. fragilis (DQ367914), $R$. fragilis (JQ711845), $R$. grisea (AY061679), R. ilicis (AY061682), R. insignis (AY061700), R. laurocerasi (AY061735), $R$. melitodes (AY061689), R. melzeri (AY061691), R. nana (AY061694), R. nauseosa (AY061733), $R$. odorata (AY061698), R. parazurea (AY061704), R. pectinata (AY061706), R. pectinatoides 


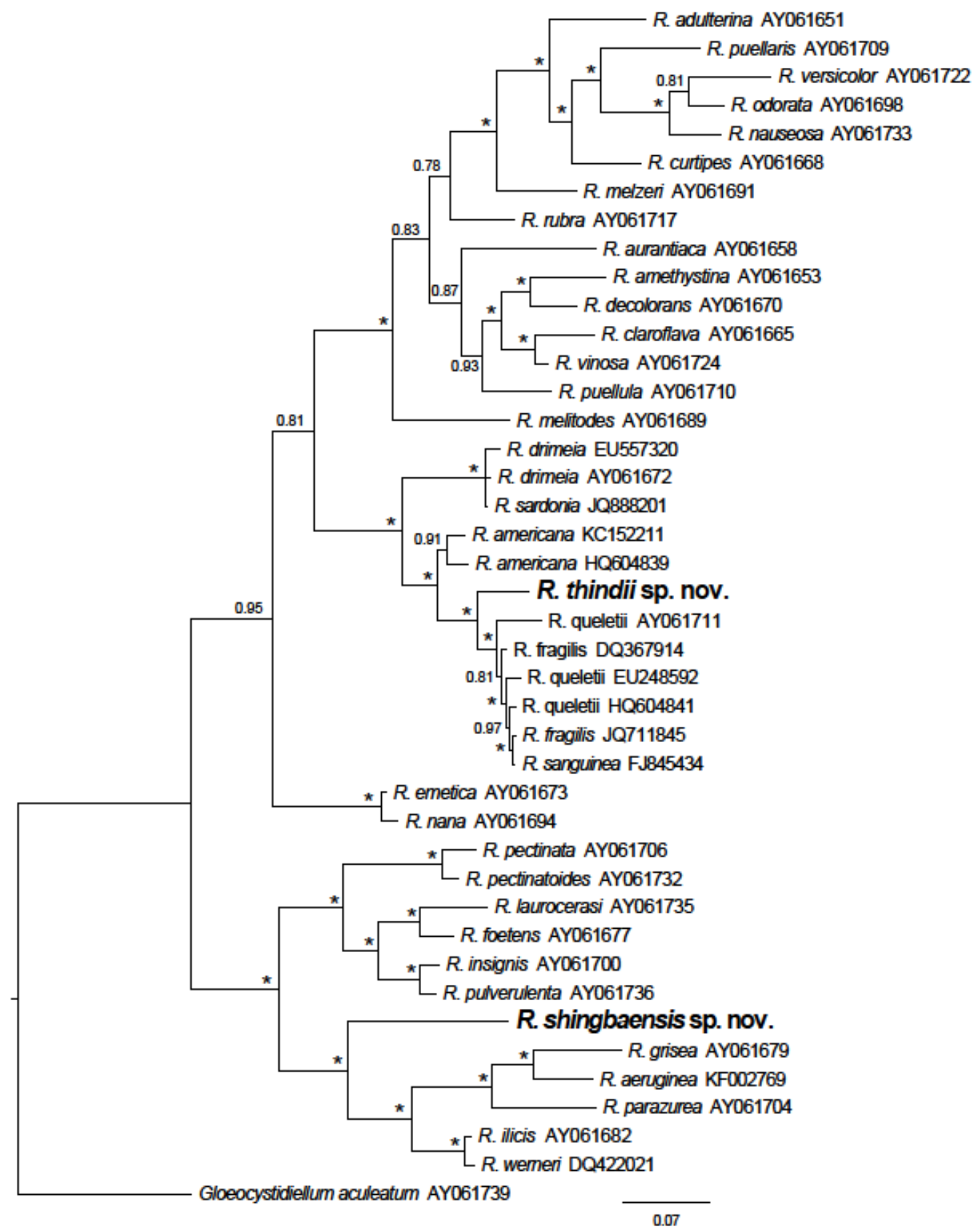

Fig. 1 - Maximum likelihood analysis of the ITS locus for Russula thindii and R. shingbaensis and a selection of Russula species, with posterior probability distribution constructed from 750000 trees from each run. An asterisk represents a posterior probability of 1, all other support is specifically listed.

(AY061732), R. puellaris (AY061709), R. puellula (AY061710), R. pulverulenta (AY061736), $R$. queletii (AY061711), $R$. queletii (EU248592), R. queletii (HQ604841), R. rubra (AY061717), $R$. sanguinea (FJ845434), $R$. sardonia (JQ888201), $R$. versicolor (AY061722), $R$. vinosa (AY061724), R. werneri (DQ422021) and the outgroup Gloeocystidiellum aculeatum (AY061739). An alignment was created from these sequences using Clustal Omega under the recommended default protocols (Sievers et al. 2011). 
Phylogenetic reconstruction for $R$. shingbaensis and $R$. thindii was performed using Bayesian inference in MrBayes v3.1.2 (Huelsenbeck \& Ronquist 2001, Ronquist \& Huelsenbeck 2003). Two independent runs of 10000000 generations with sampling every 100 generations were performed using the GTR substitution model with gamma distributed rates. Completed analysis had a split frequency below 0.01 as suggested by the authors for a well-supported reconstruction. A burnin of $25 \%$ was adequate to obtain a PSFR, potential scale reduction factor, close to a value of one indicating burnin values were suitable. The Bayesian resulting phylogenetic reconstruction was then edited in Figtree v1.4 (Rambaut 2009).

\section{Taxonomic descriptions}

Russula shingbaensis K. Das \& S.L. Mill., sp. nov.

Figs $1,2-10$

MycoBank 808081

GenBank KM386692

Etymology - after Shingba Rhododendron wildlife sanctuary, the type locality.

Type - INDIA. Sikkim: North district, Shingba Rhododendron wildlife sanctuary, on ground, subalpine coniferous forest, under Abies densa Griff., alt. 3095 m, N2743'48.6” E88 44'32.0”, 24 Aug. 2011, K. Das, KD 11-094, (holotype: BSHC, isotype: AMH).

Pileus 41-62 mm diam., at first convex with a depressed centre, becoming plano-convex with a depressed centre, then infundibuliform with maturity; surface glutinous to sticky, greyish green (a: 30B4-30C4) or greyish green (a: 30C6) with patches of orange white (a: 5A2) or darker up to citrine (b: 64), rarely reddish lilac (a: 14C3) to greyish magenta (a: 14D3), centre grayish brown (a: 9D3) to reddish brown (a: 9D4) or livid vinaceous (b: 77), sometimes slightly paler at the surrounding of the centre; margin decurved when young, slightly uplifted at maturity, tuberculately striate-sulcate. Lamellae adnexed, subdistant $(6-7 / \mathrm{cm}$ at pileus margin) after maturity, forked near stipe, cream coloured (b: 3C) or paler, unchanging after bruising; edge concolorous; lamellulae absent. Stipe $40-70 \times 7.5-12 \mathrm{~mm}$, different shaped, cylindrical to narrowly clavate with broadened or tapered base, smooth to finely longitudinally venose, yellowish white often with livid vinaceous (b: 77) tinge in places; base strigose. Context stuffed in stipe, multichambered, yellowish white, unchanging after bruising, turning pale salmon with $\mathrm{FeSO}_{4}$, dark green (b: 60) with guaiac and straw (b: 50) with KOH. Taste mild. Odor indistinctive. Spore print yellowish white (c: $30 \mathrm{Y}, 2 \mathrm{M} /$ a: $3 \mathrm{~A} 2)$.

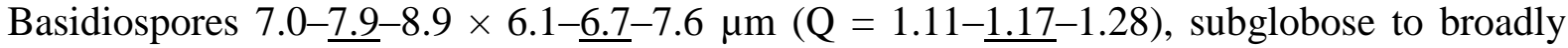
ellipsoid; ornamentation amyloid, up to $1 \mu \mathrm{m}$ high, composed of isolated warts; high warts cylindric to conic with rounded apices, never fused with each other; some low conical warts between high warts; suprahilar plage inamyloid. Basidia 36-49 × 10-12 $\mu \mathrm{m}$, subclavate, 4-spored; mature sterigmata 5-8 $\times 2-2.5 \mu \mathrm{m}$. Subhymenium up to $20 \mu \mathrm{m}$ thick, cellular. Pleuromacrocystidia 58-76 $\times 7-9 \mu \mathrm{m}$, emergent up to $20 \mu \mathrm{m}$, abundant, fusoid to lanceolate, with mucronate to capitate or appendiculated apices, thin-walled, content dense, somewhat crystal-like, grey-black with sulfobenzaldehyde. Lamellae edge sterile composed of cystidia and marginal cells. Cheilomacrocystidia 33-41 × 7-10.5 $\mu \mathrm{m}$, abundant, fusoid to lanceolate, often with capitates to appendiculated apices, thin-walled, content distinct. Lamellar trama composed of numerous sphaerocytes surrounded by connective hyphae; sphaerocytes globose to elliptical $(10-57 \times 7-43$ $\mu \mathrm{m})$; hyphae up to $5 \mu \mathrm{m}$ broad, branched, septate. Pileipellis an ixocutis to ixotrichoderm, composed of hyphae with and cystidia; hyphae subparallel to erect, composed of chains of globose to elongated inflated cells; pileocystidia 4-7 $\mu \mathrm{m}$ broad, cylindric, fusoid to lanceolate with capitates to appendiculated apices, content partially dense. Stipitipellis a thin cutis composed of parallel hyphae (up to $4 \mu \mathrm{m}$ broad), caulocystidia absent. Stipe trama composed of connective hyphae and nested sphaerocytes. Clamp connections absent in all tissues.

Additional material examined - INDIA. Sikkim: North district, Shingba Rhododendron wildlife, sanctuary, on ground, under Abies densa, subalpine coniferous forest, alt. $3095 \mathrm{~m}$, N2743'48.6” E8844'32.0”, 24 Aug. 2011, K. Das, KD 11-100 (CAL). 


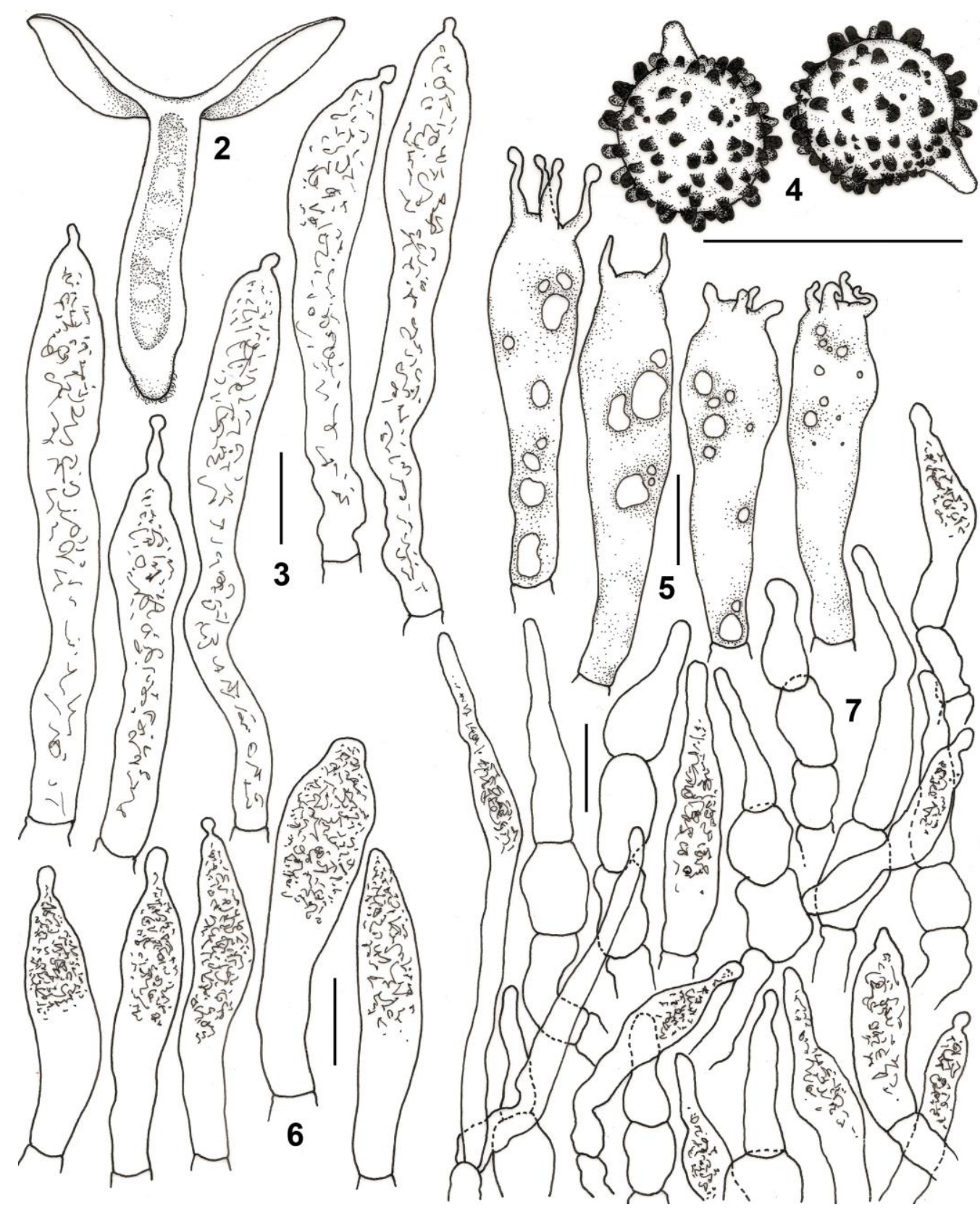

Figs 2-7 - Russula shingbaensis (KD 11-094). 2 Longitudinal section through a fresh basidioma. 3 Pleuromacrocystidia. 4 Basidiospores. 5 Basidia. 6 Cheilomacrocystidia. 7 Radial section through pileus showing the elements of pileipellis. Bars $=10 \mu \mathrm{m}$.

Notes - Russula shingbaensis is rare in the sanctuary and was not observed after 2011. It is distinct by its morphology showing the combination of striking features like, greyish-green to slightly lilac pileus with slightly tuberculately striate-sulcate margin, stipe with white and vinaceous colours in combination, multichambered stipe context, mild (indistinctive) taste, spores with isolated warts, pilear elements with chains of globose to elongated inflated cells and comparatively narrow pileocystidia. Based solely on the morphology it was quite impossible to place this taxon in any classification system as it exhibits features of both the $R$. subg. Ingratula Romagn. (tuberculately striate pilear-margin, multichambered stipe-context) and $R$. subg. Heterophyllidia Romagn. (greenish-lilac pileus, pilear elements with chains of globose to elongated inflated cells and comparatively narrow pileocystidia). Russula praetervisa Sarnari, and $R$. fragrans Romagn. which are reported from Sikkim as well, resemble in part the present species. Though $R$. praetervisa, $R$. grata Britzelm. ( $R$. subg. Ingratula) both have tuberculately striate pilear margin, multichambered stipe context and hymenial cystidia with capitate to mucronate or moniliform 


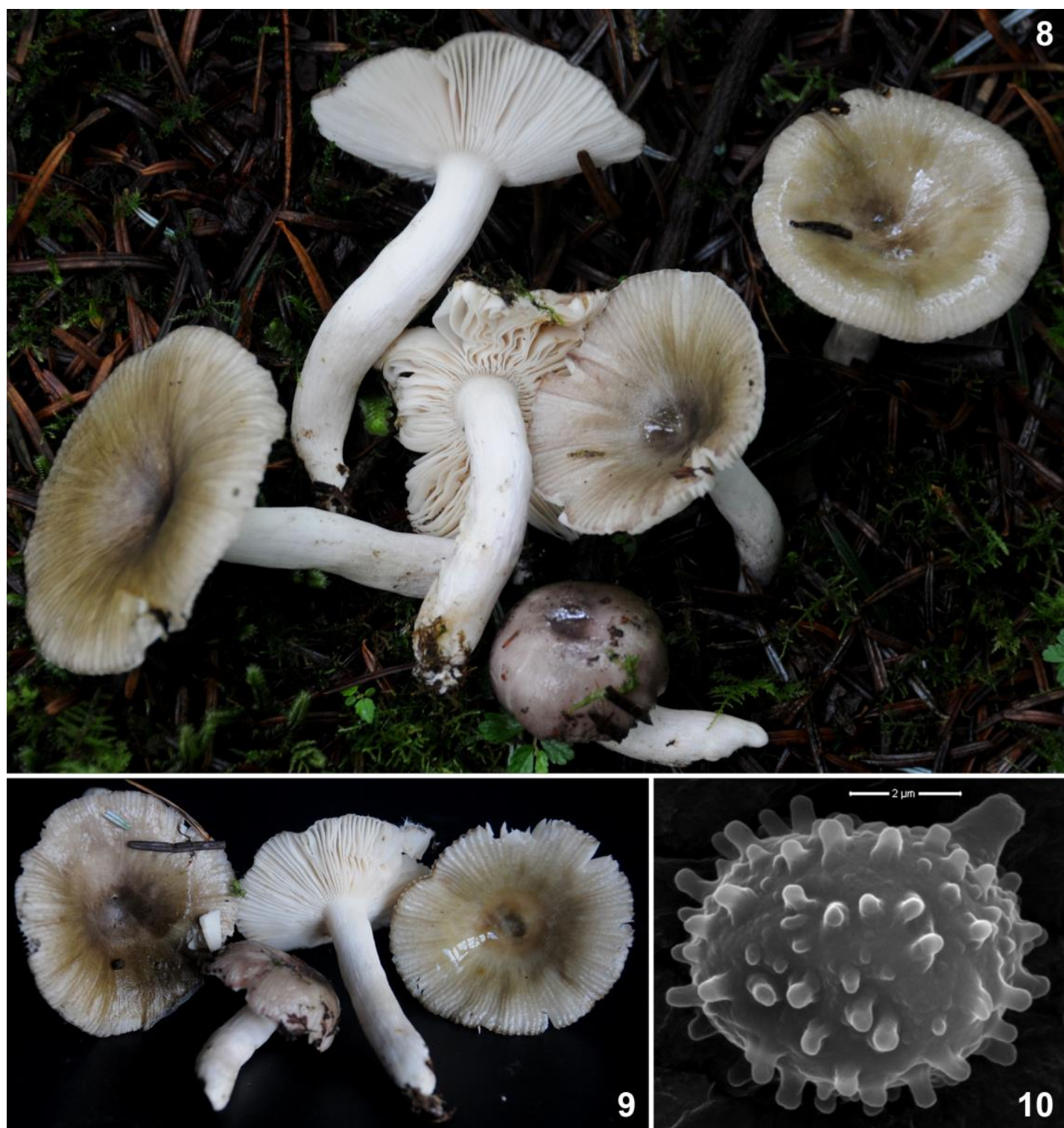

Figs 8-10 - Russula shingbaensis (KD 11-094). 8, 9 Fresh basidiomata in the field and base camp. 10 SEM images of basidiospores. Bar $=2 \mu \mathrm{m}$.

apices but, the earlier one can easily be separated from $R$. shingbaensis by the presence of reddish brown to blood-red patches on stipe base, spore-ornamentations showing warts and connectors (Sarnari 1998, Das 2013) whereas, the latter one has distinct odor of bitter almond, acrid taste and larger (7.9-10.7 × 7.2-10.6 $\mu \mathrm{m}$ ) basidiospores (Kränzlin 2005, Das 2013). Similarly, considering the macro- and micromorphology of pileipellis, three species (belonging to $R$. subg. Heterophyllidia) namely, $R$. pseudoaeruginea (Romagn.) Kuyper \& Vuure, $R$. atroaeruginea G.J. Li, Q. Zhao \& H.A. Wen and R. parazurea Jul. Schäff. (found in India as well) are also quite close to the species in discussion but, earlier three can be distinguished from $R$. shingbaensis by absence of violet tinged/flushed white stipe and multichambered stipe-context and the presence of spores with different ornamentation patterns (partial reticulum: with warts and connectors/ridges) as stated by Sarnari (1998), Kränzlin (2005), Li et al. (2013). Moreover, the unique combination of macroand micromorphological features of two subgenera ( $R$. subg. Ingratula and $R$. subg. Heterophyllidia) make this species distinct among all the known species of Russula.

Molecular analysis of the ITS locus (Fig. 1) confirmed a position grouped within the Heterophyllidia together with taxa like Russula parazurea Jul. Schäff., $R$. aeruginea Lindbl. ex Fr., $R$. grisea Fr., R. ilicis Romagn., Chevassut \& Privat etc. Russula shingbaensis is hereby placed taxonomically in the $R$. subg. Heterophyllidia. 
Etymology - to recognize Prof. K.S. Thind for his contribution to Indian mycobiota.

Type - INDIA. Sikkim: North district, Shingba Rhododendron wildlife sanctuary, on ground, subalpine coniferous forest, under Abies densa Griff., alt. 3095 m, N2743'48.6” E88 44'32.0", 24 Aug. 2011, K. Das, KD 11-095, (holotype: BSHC, isotype: AMH).

Pileus 38-77 mm diam., convex when young, gradually planoconvex, then plain or slightly upliftted to infundibuliform with maturity; surface smooth, viscid or sticky when moist, blood red to fulvous or blood red in combination of buff or to grayish ruby (a: 12C7-12D7) to cinnamon, sometimes paler up to Coral Beach at maturity; margin often faintly tuberculately striate-sulcate, incurved when young, decurved with maturity. Lamellae broadly adnate to adnexed, rather close (8-10/cm at margin), forked near stipe, cream (b: 3C), unchanging on bruising, with lamellulae in 3-4 series; edge entire, concolorous. Stipe 36-88 $\times 10-19 \mathrm{~mm}$, central, subclavate to clavate or sometimes with narrowing base; surface striate to venose, more prominent with maturity, slightly viscid, reddish white (a: 10A2-11A2) to vinaceous, base distinctly white when young, becoming saffron or light yellow to light orange (a: 4A4-5A4) with maturity or on bruising. Context firm, rather rather thin in pileus, solid to stuffed or hollow (with maturity) in stipe, yellowish white, unchanging after exposure, olivaceous grey with Guaiac, pale salmon with $\mathrm{FeSO}_{4}$ and unchanging with $\mathrm{KOH}$; taste slightly bitter then acrid; odor indistinct. Spore print pale yellow (c: $30 \mathrm{Y}, 5 \mathrm{M} / \mathrm{a}$ : 4A3).

Basidiospores 7.6- $\underline{8.6}-9.9 \times 6.1-\underline{7.0}-7.8 \mu \mathrm{m},(\mathrm{Q}=1.16-\underline{1.23}-1.32)$, broadly ellipsoid to ellipsoid; ornamentation amyloid, up to $1.1 \mu \mathrm{m}$ high, composed mostly of isolated conical to spinoid warts, rarely connected by fine connectors; plage inamyloid. Basidia 35-47 $\times 9.5-12.5 \mu \mathrm{m}$, subclavate to clavate, 2- to 4-spored, to ventricose; mature sterigmata to $7.5 \mu \mathrm{m}$ long. Pleuromacrocystidia 55-123 × 12-15 $\mu \mathrm{m}$, highly variable in length, slightly emergent to highly (to $50 \mu \mathrm{m})$ emergent, abundant, cylindric, clavate or fusoid with rounded, mucronate, subcapitate or appendiculate apices, thin-walled, content dense, somewhat crystal-like or fibrous, grey-black with sulfobenzaldehyde. Cheilomacrocystidia $41-80 \times 8-10.5 \mu \mathrm{m}$, cylindric to subfusoid, thin-walled, content dense. Subhymenium layer to $50 \mu \mathrm{m}$ thick, pseudoparenchymatous. Lamellar trama composed of numerous sphaerocytes surrounded by connective hyphae; sphaerocytes globose to elliptical $(10-57 \times 7-43 \mu \mathrm{m})$; hyphae up to $5 \mu \mathrm{m}$ broad, branched, septate. Pileipellis an ixotrichoderm, up to $60 \mu \mathrm{m}$ thick with thin glutinous layer, composed of hyaline hyphae and cystidia; hyphae to $4 \mu \mathrm{m}$ broad, branched, septate; pileocystidia 27-50 x 5-7 $\mu \mathrm{m}$, cylindric to clavate with rounded apices or subcapitate, content dense grey-black with sulfobenzaldehyde and somewhat fibrous to granular. Stipitipellis to $40 \mu \mathrm{m}$ thick, an ixocutis, elements submerged under slightly thick gluten; hyphae parallel; caulocystidia absent. Clamp connections absent in all tissues.

Additional materials examined - INDIA. Sikkim: North district, Shingba Rhododendron wildlife, sanctuary, on ground, under Abies densa, subalpine coniferous forest, alt. $3407 \mathrm{~m}$, N2745'59.6” E8843'07.9”, 28 Aug. 2011, K. Das, KD 11-114 (CAL); ibid., North district, towards Katao, on ground, under A. densa, subalpine coniferous forest, alt. $3118 \mathrm{~m}$, N2740'53.5" E8846'19.9”, 2 Sept. 2011, K. Das, KD 11-183 (CAL).

Notes - The combination of morphological characters like red coloration of pileus, viscid pileus, broadly adnate to adnexed lamellae, reddish to vinaceous stipe, acrid taste of context, pale yellow spore print, conspicuously characterized pileocystidia without any incrustations, occurrence under coniferous tree (Abies densa) undoubtedly place Russula thindii in the R. subg. Russula sect. Russula subsect. Sardoninae (Sarnari 2005). Molecular analysis of the ITS locus (Fig. 1) confirms the taxonomic placement of $R$. thindii in $R$. subsect. Sardoninae.

Two other species, Russula queletii Fr. and R. sanguinea Fr. (both reported from India as well), are quite similar (as also established by ITS sequences) in appearance and are known to be associated with coniferous trees. But, $R$. queletii can be distinguished from $R$. thindii by presence of the combination of the characters vinaceous red to violet pileus and stipe, strong fruity odor, 


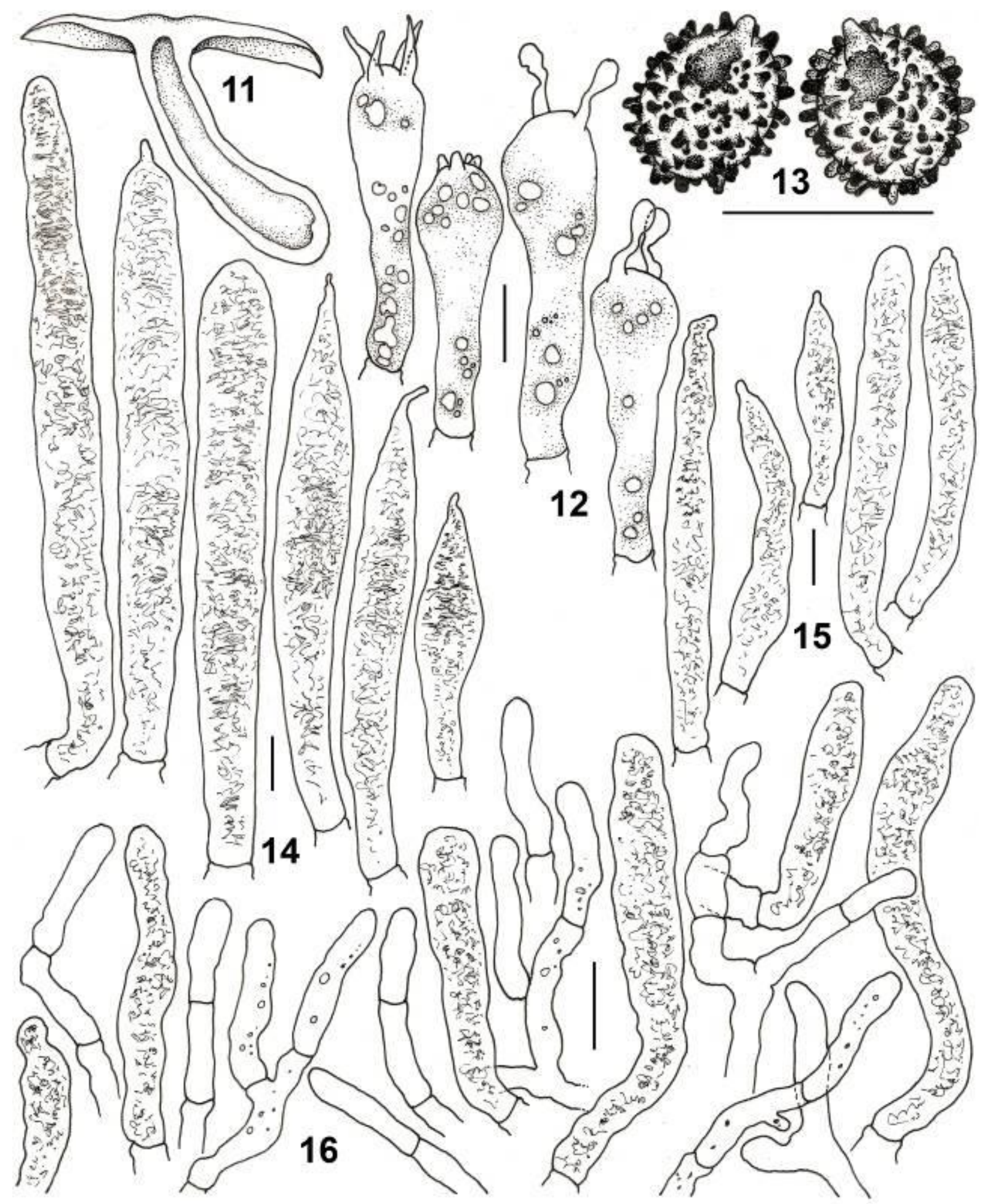

Figs 11-16 - Russula thindii (KD 11-095). 11 Longitudinal section through a fresh basidioma. 12 Basidia. 13 Basidiospores. 14 Pleuromacrocystidia. 15 Cheilomacrocystidia. 16 Radial section through pileus showing the elements of pileipellis. Bars $=10 \mu \mathrm{m}$.

absence of bitter-acrid taste, slightly paler (20 Y, 2 M) spore print, and changing of pilear context to light vinaceous red (with $\mathrm{FeSO}_{4}$ ) (Saini \& Atri 1989, Sarnari 1998, Kränzlin 2005). Similarly, $R$. sanguinea which has also a bitter and acrid taste can be separated from $R$. thindii macromorphologically, by its distinctly shorter stipe and darker spore print (40 Y, $10 \mathrm{M})$, and micromorphologically, by its cheilocystidia which have more frequent appendages (Sarnari 1998, Kränzlin 2005). 

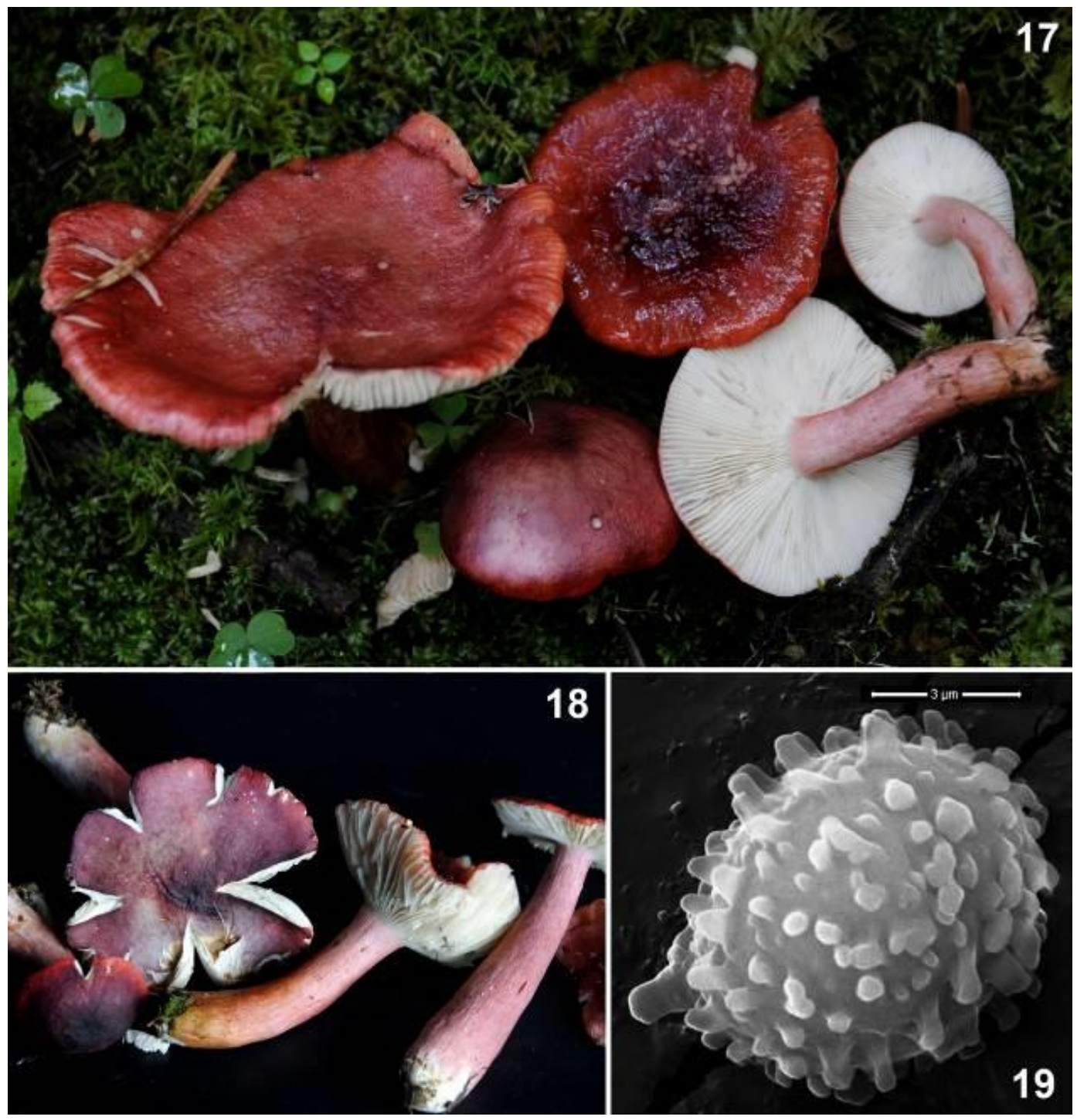

Figs 17-19 - Russula thindii (KD 11-095). 17, 18 Fresh basidiomata in the field and base camp. 19 SEM images of basidiospores. Bar $=3 \mu \mathrm{m}$.

\section{Acknowledgements}

The authors are grateful to the Director, Botanical Survey of India (BSI), Kolkata and the Department of Forest and wildlife management, Sikkim for facilitating the present study. S.K. Rai, S. Pradhan and P. Tamang (BSI, Gangtok) are thanked for helping the senior author (KD) in the field. Assistance rendered by Terry McClean (Nucleic Acid Exploration Facility, University of Wyoming, USA) for undertaking gene sequencing and Shakti Nath Das (SNBNCBS, Kolkata, India) for doing the SEM study is duly acknowledged.

\section{References}

Atri NS, Saini MK, Saini SS. 1994 - Indian Russulaceae Roze - a check list. In: Current researches in plant sciences (eds. TA Sharma, SS Saini, ML Trivedi \& M Sharma). Bishen Singh Mahendra Pal Singh, Dehradun, India, pp 81-93.

Bergemann SE, Miller SL. 2002 - Size, distribution, and persistence of genets in local populations of the late-stage ectomycorrhizal basidiomycete, Russula brevipes. New Phytologist 156(2), 313-320. 
Das K. 2013 - Diversity of ectomycorrhizal macrofungi in Sikkim Himalaya with special reference to the genera Lactarius and Russula. In: Biodiversity and environmental issues (ed. MM Sheikh). LAP Lambert academic publishing, Germany, pp 224-263.

Das K, Atri NS, Buyck B. 2013 - Three new species of Russula (Russulales) from India. Mycosphere 4(4), 707-717.

Das K, Miller SL, Sharma JR. 2006a - Russula in Himalaya 2: Four new taxa. Mycotaxon 95, 205215.

Das K, Miller SL, Sharma JR, Hemenway J. 2008 - Two new species of Russula from Western Ghats in India. Indian Journal of Forestry 31(3), 473- 478.

Das K, Miller SL, Sharma JR, Sharma P, Bhatt RP. 2005 - Russula in Himalaya 1: A new species of subgenus Amoenula. Mycotaxon 94, 85-88.

Das K, Sharma JR. 2005 - Russulaceae of Kumaon Himalaya. Botanical Survey of India, Govt. of India, Kolkata, India, pp 255.

Das K, Sharma JR, Atri NS. 2006b - Russula in Himalaya 3: A new species of subgenus Ingratula. Mycotaxon 95, 271-275.

Das K, Van de Putte K, Buyck B. 2010 - New or interesting Russula from Sikkim Himalaya (India). Cryptogamie Mycologie 31(4), 373-387.

Dowie NJ, Hemenway JJ, Miller SL. 2012 - Identity, genetic lineages and putative hybrids of an obligate mycobiont associated with the mycoheterotrophic plant Pterospora andromedea in the south-central Rocky Mountains. Fungal Ecology 5(2), 137-146.

Gardes M, Bruns TD. 1993 - ITS primers with enhanced specificity for Basidiomycetes application to the identification of mycorrhizae and rusts. Molecular Ecology 2(2), 113118.

Henderson DM, Orton PD, Watling R. 1969 - British fungus flora: agarics and boleti: colour identification chart. Royal Botanic Garden Edinburgh, UK.

Henkel TW, Aime MC, Miller SL. 2000 - Systematics of pleurotoid Russulaceae from Guyana and Japan, with notes on their ectomycorrhizal status. Mycologia 92, 1119-1132.

Holmgren PK, Holmgren NH, Barnett LC. 1990 - Index Herbariorum. Part 1: Herbaria of the world, 86th ed. Brox: New York Botanical Garden.

Huelsenbeck JP, Ronquist F. 2001 - MRBAYES: Bayesian inference of phylogenetic trees. Bioinformatics 17(8), 754-755.

Joshi S, Bhatt RP, Stephenson SL. 2012 - The current status of the family Russulaceae in the Uttarakhand Himalaya, India. Mycosphere 3(4), 486-501.

Kirk PM, Cannon PF, Minter DW, Stalpers JA. 2008 - Ainsworth \& Bisby's Dictionary of the Fungi, $10^{\text {th }}$ edition. CAB International, UK.

Kornerup A, Wanscher JH. 1978 - Methuen Handbook of Colour, Third Edition, Eyre Methuen Ltd., Reprint, London, UK.

Kränzlin F. 2005 - Fungi of Switzerland, Vol. 6. Verlag Mykologia Luzern, Switzerland.

Li GJ, Zhao Q, Zhao D, Yue SF, Li SF, Wen HA, Liu XZ. 2013 - Russula atroaeruginea and $R$. sichuanensis spp. nov. from southwest China. Mycotaxon 124, 173-188.

Manimohan P, Latha KPD. 2011 - Observations on two rarely collected species of Russula. Mycotaxon 116, 125-131.

Manjula B. 1983 - A revised list of the Agaricoid and Boletoid basidiomycetes from Nepal and India. Proc. Indian Acad sci. Plant Sci. 92, 81-214.

Miller SL, Larsson E, Larsson KH, Verbeken A, Nuytinck J. 2006 - Perspectives in the new Russulales. Mycologia 96(6), 960-970.

Miller SL, Buyck B. 2002 - Molecular phylogeny of the genus Russula in Europe with a comparison of modern infrageneric classifications. Mycological Research 106(3), 259276.

Mohanan C. 2011 - Macrofungi of Kerala. 2011 - KFRI Handbook No. 27, Kerala Forest Research Institute, Peechi, Kerala, India. 
Pradeep CK, Vrinda KB. 2010 - Ectomycorrhizal fungal diversity in three different forest types and their association with endemic, indigenous and exotic species in the Western Ghat forests of Thiruvananthapuram district, Kerala. J. Mycopathol. Res. 48(2), 279-289.

Rawla GS. 2001 - Himalayan Species of Russula Pers. Ex S.F. Gray, 1-48. In: Plant Diversity of the Himalaya (eds. PC Pande, SS Samant). Gyanodaya Prakashan, Nainital, India, pp 148.

Rambaut A. 2009 - FigTree.In. Institue of Evolutionary Biology, University of Edinburgh. Tree Figure Drawing Tool.

Ronquist F, Huelsenbeck JP. 2003 - MrBayes 3: Bayesian phylogenetic inference under mixed models. Bioinformatics 19(12), 1572-1574.

Sarnari M. 1998 - Monografia Iillustrata Del Genere Russula in Europa. Tomo Primo, Italia, pp 799.

Saini SS, Atri NS. 1989 - North Indian Agaricales XI-section Russula Pers. of Genus Russula Pers. in India. Indian J. Mycol. Pl. Pathol. 19, 44-49.

Sievers F, Wilm A, Dineen D, Gibson TJ, Karplus K, Li W, Lopez R, McWilliam H, Remmert M, Soding J, Thompson JD, Higgins DG. 2011 - Fast, scalable generation of high-quality protein multiple sequence alignments using Clustal Omega. Mol. Syst. Biol. 7, 539.

Verbeken A. 1996. Biodiversity of the genus Lactarius Pers. in tropical Africa [Doctoral dissertation]. Ghent University.

White TJ, Bruns TD, Taylor JW. 1990 - Amplification and direct sequencing of fungal ribosomal RNA genes for phylogenetics. In: PCR protocols: a guide to methods of Amplifications (eds. M Innis, D Gelfand, J Sninsky, T. White). Academic Press New York, New York, USA. 